\title{
Effect of Operational Parameters on the Production of a Solar Distiller Coupled to a Hybrid Photovoltaic Thermal Collector
}

\author{
Maifi Lyes", Kerbache Tahar, Hioual Ouided, Chari Abdelhamid \\ Laboratory Physics Chemistry of Semi Conductor, Physics Department, Exact Sciences Faculty, Constantine University, Constantine, \\ Algeria
}

Email address:

maifi@umc.edu.dz (M. Lyes), tkerbache@yahoo.fr (K. Tahar)

${ }^{*}$ Corresponding author

\section{To cite this article:}

Maifi Lyes, Kerbache Tahar, Hioual Ouided, Chari Abdelhamid. Effect of Operational Parameters on the Production of a Solar Distiller Coupled to a Hybrid Photovoltaic Thermal Collector. American Journal of Energy Engineering. Vol. 5, No. 1, 2017, pp. 1-5.

doi: $10.11648 /$ j.ajee.20170501.11

Received: September 2, 2016; Accepted: December 1, 2016; Published: February 21, 2017

\begin{abstract}
It is universally recognized that the lack of water on the one hand, and the depletion of fossil fuels on the other hand are one of the major challenges of our century, the face these critical issues, desalination of salt water and/or brackish water appears as one of the possible solutions to the survival of humanity. Among the techniques used in this field, and needs relatively low drinking water, solar distillation can be a very good solution especially for arid and desert zones. In order to improve the production of solar stills, our work focuses on the coupling of a flat plate solar distiller with a flat collector to ensure preheating distilled water. We prepared heat balances at the distiller and describe their sensor transient thermal behavior. Next, we used the RK4 method to solve systems of equations obtained. The numerical results clearly show the influence of various parameters on the daily production of this system.
\end{abstract}

Keywords: Flat Plate Distiller, Collector, Preheating, Production, Sensor

\section{Introduction}

Problems of environmental pollution and energy lack in the world have become much serious recently. Solar energy as a renewable and environmentally friendly energy has the potential to meet global energy demand in the future. Methods for the conversion of solar energy can be classified into two types: a thermal option, that converts solar energy into heat, subsequently transformed into electricity, and the photovoltaic methods that converts solar energy directly into electrical energy. Therefore, there is a need to develop an ingenious method of solar energy conversion systems and then to substitute it where applications of fossil fuels are most vulnerable. One of the ingenious methods of solar energy conversion systems is the photovoltaic thermal solar collector or hybrid solar collector, which converts solar radiation directly to both thermal and electrical energies. It is very attractive for solar applications in which limited space and area related installation cost are of primary concern. The hybrid collector is also attractive when the space needed to install side-by-side solar thermal and photovoltaic collectors is not readily available.

Need of drinking water in the world is increasing continuously, while underground reserves are contently reduced. More than a third of humanity, mostly belonging to third world countries, do not have access to drinking water. The drinking water supply is one of the most serious problems of our time, as water demand reached believes that natural resources tend to diminish or disappear. Desalination of seawater or darkish can contribute to increased water potential; however, this method requires a lot of energy which is involved in the cost of water. In areas with strong sunlight solar distillation then appears as a very attractive solution. However, the problem is the low efficiency of this type of process. And also to overcome this drawback is we are planning in the context of this work to couple the solar still with a flat plate solar thermal collector. We still consider the numerical simulation of an active solar. Particular attention is paid to the effect of some parameters (ambient 
temperature, the thickness of the layers of water ....) on the cumulated production of distilled water.

\section{The Mathematical Model}

The studied system is a solar still coupled with a solar collector. The model is established by taking the following assumptions [1-3].

- The sun is assimilated to a black body.

- The temperature of each component is uniform because the temperature gradient is negligible with respect to the space.

- The side walls are assumed adiabatic.

- The condensation takes place only on the cover (there is no condensation on the sides)

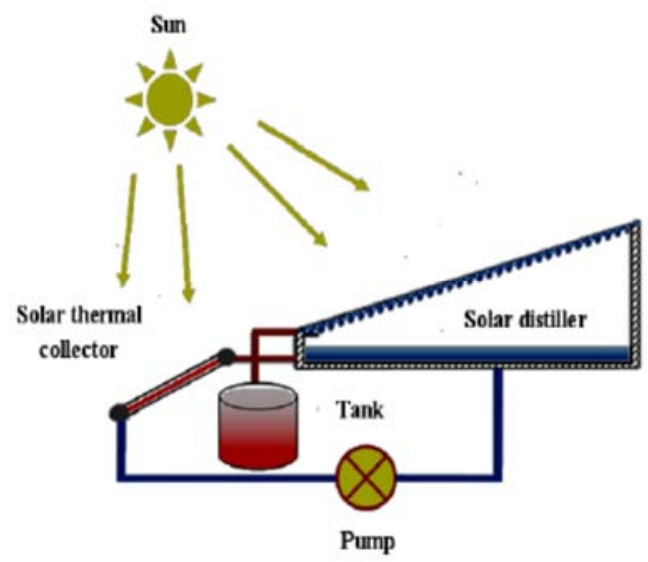

Figure 1. Schematic diagram of an active solar still coupled with a photovoltaic/thermal collector.

\section{The energy Balance}

Equations that characterize the running of flat plate solar distiller in transient regimes are given respectively by:

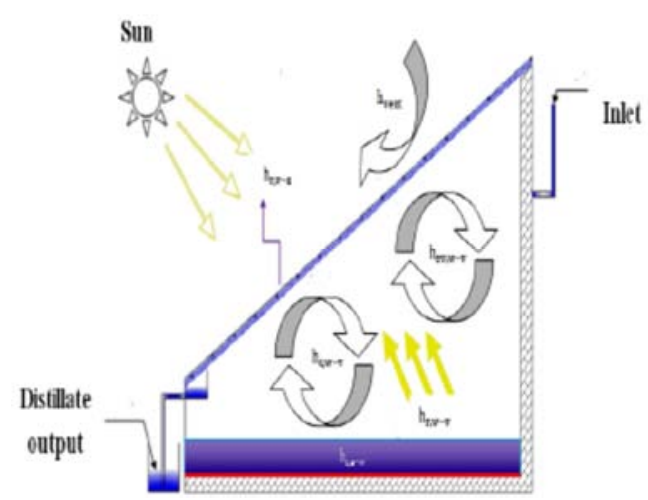

Figure 2. Cross sectional view of a single-slope passive solar still.

\subsection{At the Level of Coverage}

$$
\begin{gathered}
m_{v} C_{p v} \frac{d T_{v}}{d t}=G a_{v}+\left(h_{r, w-v}+h_{c, w-v}+h_{e v, w-v}\right)\left(T_{w}-\right. \\
\left.T_{v}\right)-h_{\text {wind }}\left(T_{v}-T_{a m}\right)-h_{r, v-a}\left(T_{v}-T_{c}\right)
\end{gathered}
$$

\subsection{At Brine Level}

$$
\begin{gathered}
m_{w} C_{p w} \frac{d T_{w}}{d t}=G a_{w}+\left(h_{r, w-v}+h_{c, w-v}+h_{e v, w-v}\right)\left(T_{w}-\right. \\
\left.T_{v}\right)-h_{c, a-w}\left(T_{a}-T_{w}\right)
\end{gathered}
$$

\subsection{At the Absorbent Tray Level}

$m_{a} C_{p a} \frac{d T_{a}}{d t}=G a_{a}+h_{c, a-w}\left(T_{a}-T_{w}\right)-h_{p e r t a}\left(T_{a}-T_{i s i}\right)$

\subsection{At the Insulator Level (Interior Face)}

$$
\frac{m_{i s}}{2} C_{p i s} \frac{d T_{i s i}}{d t}=h_{p e r t a}\left(T_{a}-T_{i s i}\right)-h_{p e r t a}\left(T_{i s i}-T_{i s e}\right)
$$

\subsection{At the Insulator Level (Exterior Face)}

$$
\begin{gathered}
\frac{m_{i s}}{2} C_{p i s} \frac{d T_{i s e}}{d t}=h_{\text {pertis }}\left(T_{i s i}-T_{i s e}\right)-h_{r, i s-s o l}\left(T_{i s i}-T_{i s e}\right)+ \\
h_{\text {wind }}\left(T_{i s e}-T_{a m}\right)
\end{gathered}
$$

\section{The Coefficients of Heat Transfer}

\subsection{Calculation of the Coefficient of Heat Transfer by Convection}

Between the ambient environment and the outer surface of the glass [4-6]:

$$
h_{\text {wind }}=5.7+3.8 V_{\text {wind }}
$$

Between the inner pane and the body of water [7-9]:

$$
\begin{gathered}
h_{c, w-v}=0.884\left(\left(\left(T_{w}-T_{v}\right)+\frac{P_{w}-P_{v}}{268900-P_{w}}\right)\left(\frac{1+\cos (\beta)}{2}\right)^{1 / 3}\right. \\
P_{v}=\exp \left(25.317-\left(\frac{5144}{T_{v}+273.15}\right)\right. \\
P_{w}=\exp \left(25.317-\left(\frac{5144}{T_{w}+273.15}\right)\right.
\end{gathered}
$$

Between the absorber and the water mass [10]:

$$
h_{c, a-w}=\left(\frac{0.27 \lambda_{w}}{L_{w}}\right)\left(G r_{w} P r_{w}\right)^{0.25}
$$

Gr: Grashof number [11]:

$$
G r=\frac{g \beta_{w}\left(T_{a}-T_{w}\right) L_{c r a c, a}}{v_{m e}^{2}}
$$

Pr:Brandt number:

$$
P r_{w}=\frac{\mu_{w} C_{p w}}{\lambda_{w}}
$$

\subsection{Calculation of the Coefficient of Heat Transfer by Radiation}

The surface solar power absorber by the water mass [12]:

$$
G a_{v}=G_{g} \alpha_{v} A_{v}
$$

Solar power absorber by the surface of the water mass:

$$
G a_{w}=G_{g} \alpha_{w} A_{w}
$$

Solar power absorber by the absorber:

$$
G a_{a}=G_{g} \alpha_{a} A_{a}
$$


Between the glass and the water mass:

$$
h_{r, w-v}=A_{w} \sigma \frac{\left(T_{w}+T_{v}\right)\left(T_{w}^{2}+T_{v}^{2}\right)}{\frac{1}{\varepsilon_{w}}+\frac{1}{\varepsilon_{v}}-1}
$$

Between the insulator and the ground:

$$
h_{r, i s-s}=A_{w} \sigma \varepsilon_{i s} \frac{\left(T_{W}^{4}+T_{v}^{4}\right)}{\left(T_{i s e^{-T}}\right)}
$$

Between the ambient environment and the exterior surface of the glass:

$$
h_{r, v-a}=A_{v} \sigma \varepsilon_{v}\left(T_{c}^{2}+T_{v}^{2}\right)\left(T_{c}+T_{v}\right)
$$

\subsection{Calculation of the Coefficient of Heat Transfer by Evaporation}

Between the glass and water mass $[10,13,14]$ :

$$
h_{e v, w-v}=16.276 .10^{-3} h_{c, w-v}\left(\frac{\left.P_{w}-P_{v}\right)}{\left.T_{w}-T_{v}\right)} A_{w}\right.
$$

\subsection{Calculation of the Coefficient of Heat Transfer by Conduction}

Between the insulator and the absorber (inside):

$$
h_{\text {perta }}=\frac{2 \lambda_{\text {is }}}{\delta_{\text {is }}}
$$

Between the interior insulator and the exterior insulator:

$$
h_{\text {pertis }}=\frac{\lambda_{\text {is }}}{\delta_{\text {is }}}
$$

\section{Results and Discussion}

After establishing the balances reflecting thermal behavior of the hybrid sensor photovoltaic thermal and the distiller in transient state, non-linear systems and coupled differential equations obtained are solved by the Runge-Kutta $4 \mathrm{TH}$ order method. For the evaluation of operating parameters, a computer program is developed in FORTRAN language for solving heat balance equations for different elements. The input parameters of the computer program include weather for the city of Constantine, Algeria (latitude $36^{\circ}, 17$ north, longitude $6^{\circ}, 36$ east, and a time difference of one hour), 18 august was chosen as the calculation date (date of the month representative) under normal conditions. The thermo physical parameters and settings are displayed in Table 1.

Table 1. The thermo-physical parameters [15].

\begin{tabular}{lll}
\hline The glass & The basin & insulation \\
\hline$\delta_{v}=3 \mathrm{~mm}$ & $\delta_{a}=0.2 \mathrm{~mm}$ & $\delta_{i}=4 \mathrm{~cm}$ \\
$\lambda_{v}=0.93 \mathrm{~W} \cdot \mathrm{m}^{-1} \cdot \mathrm{K}^{-1}$ & $\lambda_{v}=300 \mathrm{~W} \cdot \mathrm{m}^{-1} \cdot \mathrm{K}^{-1}$ & $\lambda_{i}=0.051 \mathrm{~W}^{-1} \cdot \mathrm{m}^{-1} \cdot \mathrm{K}^{-1}$ \\
$\rho_{v}=2530 \mathrm{Kg} \cdot \mathrm{m}^{-3}$ & $/$ & $/$ \\
$C_{p v}=836 \mathrm{~J} \cdot \mathrm{Kg}^{-1} \cdot \mathrm{K}^{-1}$ & $/$ & $/$ \\
$\varepsilon_{v}=0.83$ & $\varepsilon_{a}=0.03$ & $\varepsilon_{i}=0.83$ \\
$\alpha_{v}=0.66$ & $/$ & $/$ \\
$A_{v}=1.46 \mathrm{~m}^{2}$ & $A_{a}=1 \mathrm{~m}^{2}$ & $/$ \\
\hline
\end{tabular}

It is evident that the production of distiller depends closely on the quantity of heat received thus an improving of evaporation process and therefore a higher production Fig. 3.

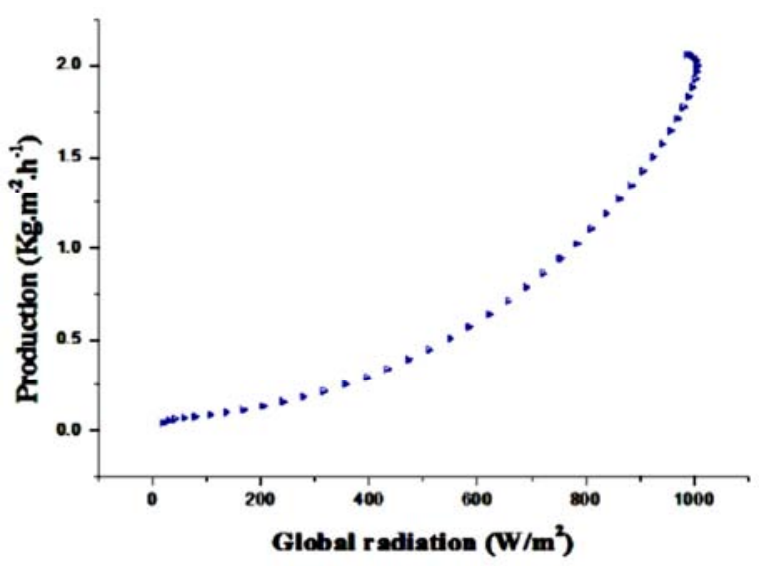

Figure 3. Effect of solar flux on the production of distilled.

Fig. 4 Shows the variation in the cumulative production of distilled water with room temperature, allowing to note the increase in production until the value of $43^{\circ} \mathrm{C}$, too high beyond the ambient temperature leads to an increase in glass temperature which will have an adverse effect on the condensation and therefore on production.

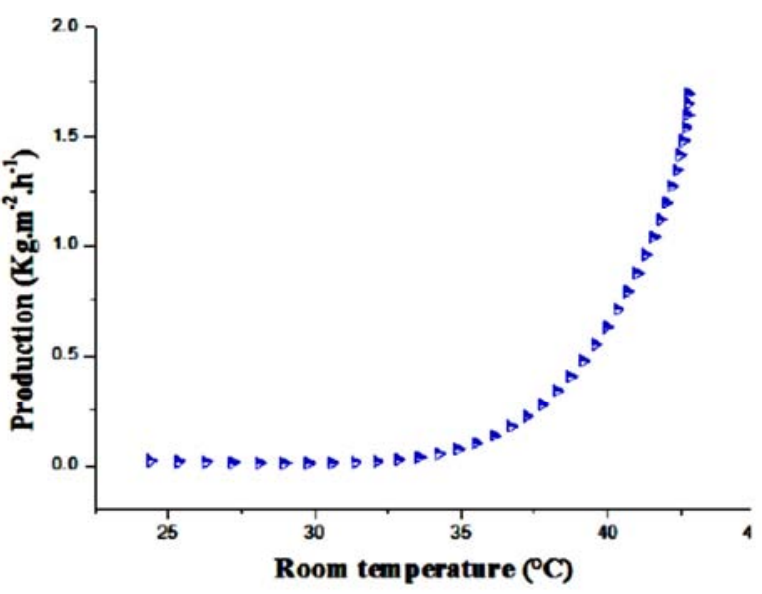

Figure 4. Effect of water temperature of the production of distillate.

The cumulative production of distilled water is zero during the first hours of the day (before $8 \mathrm{am}$ ) for both systems (with and without preheating), we note that the running temperature of the flat plate distiller with preheating starts before temperature of distiller without preheating. Fig. 5 from this moment it appears a difference in production between the distiller and the coupled system, which increases with the growth of the solar radiation reaching a maximum at 
$13 \mathrm{~h}$ for the coupled system and $14 \mathrm{~h}$ for the flat plate distiller. Where the hourly production of plate distiller is $1.6 \mathrm{Kgm}^{-2} \mathrm{~h}^{-}$ 1 , while that of the coupled system reaches $2.3 \mathrm{Kgm}^{-2} \mathrm{~h}^{-1}$.

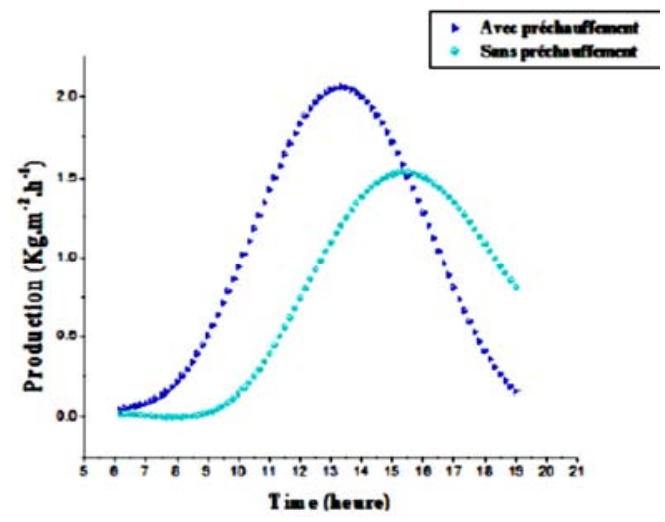

Figure 5. Temporal variation in the production of distilled water.

It is easy to see in Fig. 6 when the temperature between the water and glass $\left(\mathrm{T}_{\mathrm{w}}-\mathrm{T}_{\mathrm{v}}\right)$ increases, there is an increase in production resulting from increased evaporation rate.

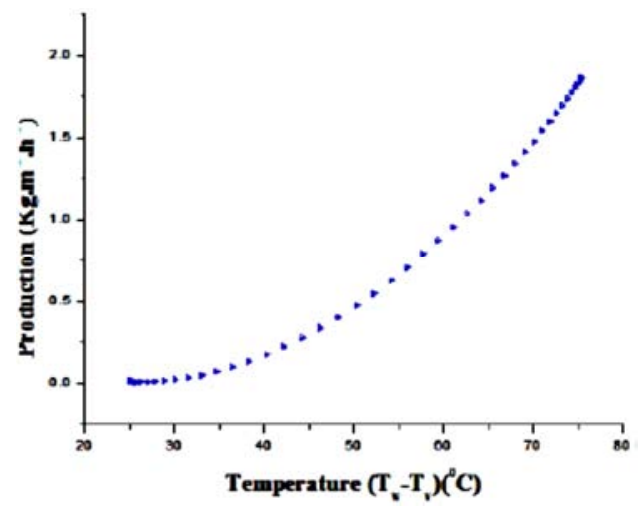

Figure 6. The effect of the temperature difference on the production.

In the Fig. 7 the effect of inlet temperature on the hot feed distillate stream is four feed rates, to the configuration of the air gap. Thank you to the logarithmic scale of the y-axis, a clear exponential trend is observed for all flow rates. This was expected due to the dependence of the flow of distillate to the difference in vapour pressure, which in turn depends exponentially on the temperature on the temperature according to a modified Antoine equation.

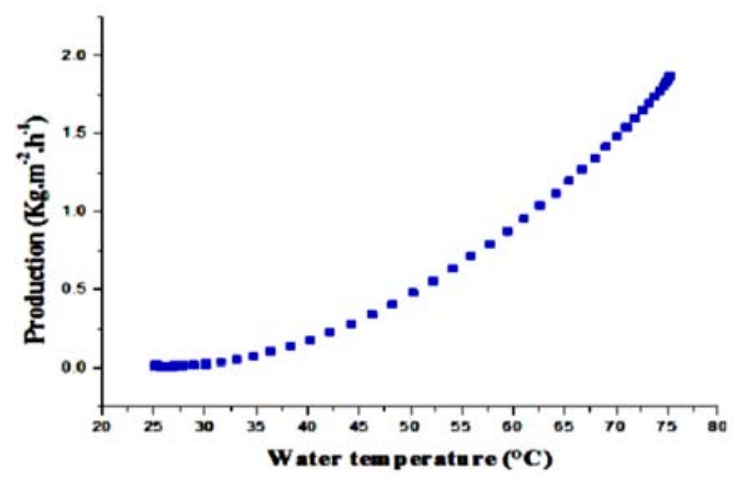

Figure 7. The effect of the water temperature on the production of distillate.
The effect of the thickness of the brine on production, a flat plan distiller plane is highlighted in Fig. 8 and shows clearly that in all cases the reduction of the thickness of the layer water leads to the increase of the characteristics of distillers. The experimental results obtained by Badran. O. O [6], shows that the evolution of the thickness of the sheet of water, cause the decrease of the production of distilled water.

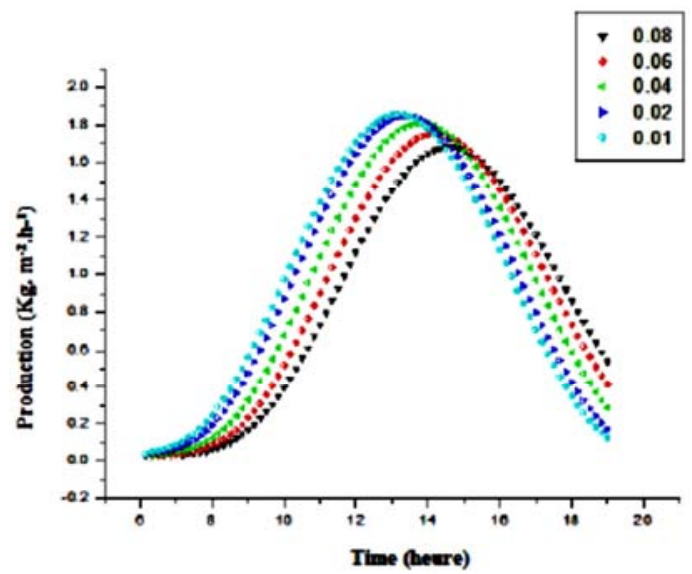

Figure 8. Effect of the water layer on the production of distillate water.

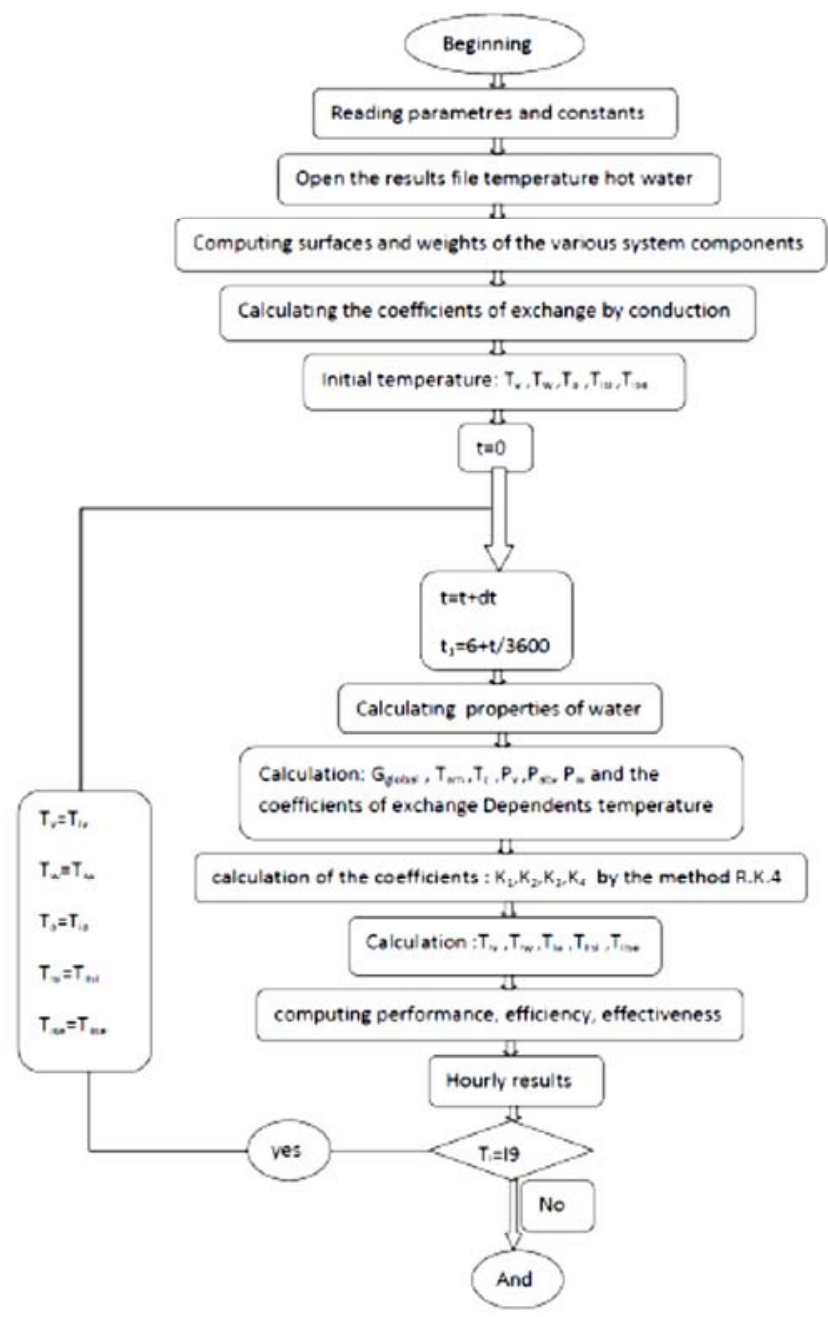

Figure 9. Algorithm for the simulation. 


\section{Conclusion}

Solving the system of equations governing the running of the solar stiller coupled with a flat plate collector was discussed by the order 4 Runge-Kutta method. The results obtained allow us to advance the following conclusions: Solar radiation is the parameter most affecting the running of a solar stiller. The increase of the ambient temperature leads to an increase in production. And increasing the temperature difference between the glass and the brine leads better production of distilled water. Increasing the water layer decreases the production of distilled water. The preheating improves the production of flat plan distiller $37 \%$.

\section{Nomenclature}

\section{A}

$\mathrm{Cp}$

Ga

$\mathrm{g}$

Gr

h

L

$\mathrm{m}$

$\mathrm{Pa}$

$\rho$

$\mathrm{T}$

$\mathrm{t}$

V

$\alpha$

$\beta$

$\lambda$

$\mu$

$\sigma$

$\varepsilon$

$\delta$

$v_{m e}$

subscripts

a

am

c

e

ev

i

is

$\mathrm{V}$

$\mathrm{r}$

w

pert
Surface area

Specific heat

Solar power absorbed

gravitational acceleration

Grashof number

Heat transfer coefficient

length

Mass flow rate

Prandtl number

density

Temperature

Time variable

Velocity

Absorptivity

thermal expansion coefficient

Thermal conductivity

Dynamic viscosity

Boltzmann number

Emissivity

Air-vapor mixture kinematic viscosity

absorbor

ambient

Convection/ sky

exterior

evaporation

inferior

insulating

glass

radiation

water

Loss $\mathrm{m}^{2}$

$\mathrm{J} \cdot \mathrm{Kg}^{-1} \cdot \mathrm{K}^{-1}$

W. $\mathrm{m}^{-2}$

$\mathrm{m} . \mathrm{s}^{-2}$

/

$\mathrm{W} \cdot \mathrm{m}^{-2} \cdot \mathrm{K}^{-1}$

$\mathrm{m}$

Kg.s ${ }^{-1}$

/

$\mathrm{Kg} / \mathrm{m}^{3}$

${ }^{\circ} \mathrm{K}$

$\mathrm{S}$

$\mathrm{m} \cdot \mathrm{s}^{-1}$

/

$\mathrm{K}^{-1}$

$\mathrm{W} \cdot \mathrm{m} \cdot \mathrm{K}^{-1}$

Kg. $\mathrm{m}^{-1} \cdot \mathrm{s}^{-1}$

\section{References}

[1] Kern. Hanson, W. Zachritz, K. Stevens, L. Mimbela, R. Polka, L. Cisneros, Distillate Water Quality of a Single-Basin Solar Still: Laboratory and Field Studies, Solar Energy,vol.76, 635645, 2004.

[2] W. A. Kamal, A Theoretical and Experimental Study of the Basin- Type Solar Still Under The Arabian Gulf Climatic Conditions, Solar and Wind Technology, vol.5, 147-157, 1988.

[3] A. A. Al-Karaghouli, W. E. Alnaser, Performances of Single and Double Basin Solar-Stills, Applied Energy, vol.78, 347354, 2004.

[4] Duffine. A, Beckman. W. A, Solar Engineering of Thermal Processes. New York, John Wiley \& Sons, 1991.

[5] Zhang. H. F, Utilization Principle and Computer Simulation of Solar Energy (in Chinese), 2nd ed. Xi'an: Xi' an Northwestern Polytechnical.

[6] O. O. Badran, M. M. Abu-Khader, Evaluating thermal performance of a single slope solar stilll, Heat Mass Transfer (2007) 43:985-995.

[7] S. Sharples, P. S. Charlesworth, Full-scale measurements of wind- induced convective heat transfer from a roof-mounted flat-plate solar collector, Sol. Energy, vol. 62 (1998) 69-77.

[8] K. S. Ong, T. T. Chow, Performance of solar chimney, Journal of Solar Energy, Vol. 74, (2003).

[9] Abdulhaiy. M. Radhan, Transient analysis of a stepped solar for heating and humidifying greenhouszs, Désalination, 161(2004) 89-97.

[10] R. V. DUNKLE, Solar water distillation: The Roof Type Still and a multiple diffusion Still, Commonwealth scientific and industrial research organization, Victoria, Australia, 895-902 edition 1961.

[11] W. A. KAMAL, A Theorical and Exprimantal study of the basin- type solar still under the Arabian Golf Climatic Condition, Solar \& wind technology, vol.5 ํ2, pp 147, Edition 1988.

[12] Hakan, F. Oztop, Fatih. Bayrak, ArifHepbasli. Energetic and exergetic, aspects of solar air heating (solar collector) systems Renewable and Sustainable, Energy Reviews vol 21 (2013) 59-83.

[13] Sopian. K, Liu. H. T, Kakac. S, Performance of a double pass photovoltaic thermal solar collector suitable for solar drying systems. Energy Convers Manage, vol 41(4): 353-365.

[14] Othman. M. Y, Yatim. B. Performance analysis of a doublepass photovoltaic/thermal (PV/T) solar collector with CPC and fins, Renewable Energy, 2007, 32(13): 2223-2241.

[15] Sharples. S, charlesworth. P. S. Full-scale measurements of windinduced convective heat transfer form a roof-mounted flat-plate solar collector. Sol energy, 1998, 62(2):69-77. 